\title{
Energy Expenditure and Fitness Response Following Once Weekly Hill Climbing at Low Altitude
}

Authors

Affiliations

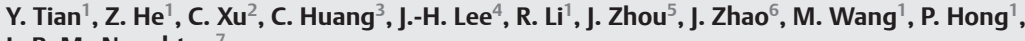
L. R. Mc Naughton

Affiliation addresses are listed at the end of the article
Key words

- $\mathrm{VO}_{2} \max$

- resting metabolic rate

- body composition

- physical activity

accepted after revision

August 28, 2014

\section{Bibliography}

DOI http://dx.doi.org/

10.1055/s-0034-1395520

Published online:

January 21, 2015

Int J Sports Med 2015; 36:

357-364 @ Georg Thieme

Verlag KG Stuttgart · New York

ISSN 0172-4622

\section{Correspondence}

\section{Prof. Ye Tian}

Biology Center

China Institute of Sport Science

11 Tiyuguan Rd. dongcheng

District

Beijing

China 100061

Tel.: + 86/10/87182528

Fax: $+86 / 10 / 87182600$

tianye@ciss.cn

\section{Abstract}

This work sought to determine the fitness responses and energy expenditure (EE) following once-weekly hill climbing for 16 weeks on different slopes. A cohort of 98 healthy, sedentary subjects ( 49 female, 49 male) completed the program at their preferred climbing pace. Body composition, resting metabolic rate (RMR) and $\mathrm{VO}_{2} \mathrm{max}$ were measured. EE was measured on 4 slopes $\left(11.6^{\circ}, 19.9^{\circ}, 14.9^{\circ}\right.$, and $\left.28.6^{\circ}\right)$ at the subjects' preferred speed. In males, weight, body mass index, fat mass significantly decreased $(P<0.05)$, and RMR showed an increasing trend, but the difference was not significant $(P=0.051)$. In females, the muscle mass increased significantly, and fat

\section{Introduction}

\section{$\nabla$}

The higher prevalence of obesity [12] may reflect the imbalance between energy intake and expenditure, where energy intake exceeds energy expenditure over some period of time. Similarly, weight loss can occur only when energy expenditure is elevated above energy intake for a period of time. Finally, when energy intake is matched to energy expenditure, body weight remains constant [15]. To achieve significant safe weight loss, a minimum energy intake of $5040 \mathrm{~kJ} /$ day for women and $6300 \mathrm{~kJ} /$ day for men, respectively [38], has been suggested. There is an inverse linear dose-response relationship between volume of physical activity and allcause mortality, and an energy expenditure of about $4200 \mathrm{~kJ} /$ week is associated with a significant $20-30 \%$ reduction in risk of all-cause mortality [13]. Approximately 31\% (95\% CI 30.9-31.2) of adults are physically inactive, with proportions ranging from $17.0 \%$ in southeast Asia to about $43 \%$ in the Americas and the eastern Mediterranean [16]. Increased physical activity (PA) and exercise training (ET) is therefore recom-
(\%) and fat mass significantly decreased $(\mathrm{P}<0.05)$. Absolute and relative of $\mathrm{VO}_{2} \max$, ventilation $(\mathrm{VE})$ improved significantly in both sexes $(\mathrm{P}<0.01)$. Energy expenditure was similar on different slopes, but shows gender-specific values of approximately 50.4 and $33.6 \mathrm{~kJ} / \mathrm{min}$ for males and females, respectively. The regression equation of $\mathrm{EE}(\mathrm{kJ} / \mathrm{min})=[1.724 \times($ female $=1$, and male $=2)+(-0.072 \times$ age $)+0.106 \times$ weight $+0.024 \times$ $\mathrm{HR}+0.136 \times$ slope $+1.487 \times$ velocity] $\times 4.2$. In conclusion, hill climbing at a subjects' preferred velocity is a vigorous-intensity physical activity for energy cost and, performed once weekly, enhances cardiorespiratory fitness and reduces fat mass, therefore making it a viable exercise for most people.

mended for improving energy expenditure [21] and as a component of weight management for prevention of weight gain, for weight loss, and for prevention of weight regain after weight loss $[11,49]$. Increased PA and ET have been included in $88 \%$ of successful weight loss and weight maintenance intervention programs [38]. A negative energy balance generated by PA/ET will result in weight loss, and the larger the negative energy balance, the greater the weight loss [11]. A dose effect is apparent for PA and weight loss, and higher doses are capable of providing $3 \%$ or greater weight loss from initial weight [11]. Exercise expenditure $>10500 \mathrm{~kJ} /$ week were substantially better at promoting long-term weight loss than that of $<4200 \mathrm{~kJ}$ activity/week and 4200 $10500 \mathrm{~kJ}$. Specifically, 2.5 years after baseline, participants reporting $>10500 \mathrm{~kJ}$ activity/week lost an average of $7 \mathrm{~kg}$ from baseline weight, whereas the other 2 groups had average weight losses of $<1 \mathrm{~kg}$ [50]. Resting metabolic rate (RMR) accounts for $60-70 \%$ of daily energy expenditure and any interventional behavior that chronically alters RMR may have important implications for energy-balanced weight control [47]. Exercise is 
a possible means to increase RMR, which could offset age-related metabolic declines and facilitate weight management [36]. As such, exercisers are intuitively concerned about the calories used when exercising. They would like to know whether a particular physical activity is effective in expending the desired amount of calories. Thus, understanding and accurately assessing the energy expenditure of different types of physical activity is important for exercise prescription and for recommending the dose-dependent physical activity.

While climbing and mountaineering sports are gaining more and more public interest [41], most research concerning the energy cost of mountaineering has focused on high-altitude expeditions ( $>4000 \mathrm{~m}$ ) [30], moderate altitude (2500-3800 m) [5] and rock climbing [14]. Low-intensity physical exercise in normobaric hypoxia $\left(15 \% \mathrm{O}_{2}, \approx 2500 \mathrm{~m}\right)$ leads to more weight loss in obese people than low-intensity physical exercise in normobaric sham hypoxia [33]. Very little data are available concerning the physical activity of hill climbing at low altitude. Stairway climbing has been shown to be effective in burning calories [17,51] and in improving cardiovascular fitness [4]. Single-step stairway climbing used $35.7 \mathrm{~kJ} / \mathrm{min}$ [17] or $42.84 \mathrm{~kJ} / \mathrm{min}$ [51] during ascent at speeds chosen by the participants. Relative to controls, the stair-climbing group displayed a $17.1 \%$ increase in $\mathrm{VO}_{2} \max$ [4], which is regarded as the gold standard in cardiorespiratory fitness assessment [26]. Physical activity plays a critical role in improving cardiovascular health [53] and is generally associated with more favorable cardiovascular biomarker levels than inactivity, and higher levels of cardiorespiratory fitness are associated with a lower risk of developing health problems [13]. There are currently no studies that have investigated the effects of hill climbing on cardiorespiratory fitness and energy expenditure at different slopes.

Overweight and obese individuals as well as persons of average weight often report not having time to exercise [53]. But how much physical activity is a minimum threshold of intensity needed to improve cardiorespiratory fitness [11]? Studies have supported a dose-response relationship between chronic physical activity levels and health outcomes [13], such that greater benefit is associated with higher amounts of physical activity. However, findings are inconsistent. As a result, data regarding the specific quantity and quality of physical activity for the attainment of the health benefits are less clear and need to be further studied.

The purpose of this study was therefore to determine body composition, RMR and cardiorespiratory $\left(\mathrm{VO}_{2} \mathrm{max}\right)$ responses after hill climbing once a week for 16 weeks at an altitude of $565 \mathrm{~m}$ and to measure the EE under different slope angles at the subjects' preferred speed during a hill climbing session.

\section{Method}

$\nabla$

\section{Subjects}

Prior to testing, the subjects were instructed to complete questionnaires about their recreational activities, medical history and physical status. A group of 98 (49 females, $44 \pm 10$ years, $161.1 \pm 5.9 \mathrm{~cm}, 59.2 \pm 8.3 \mathrm{~kg}, 22.78 \pm 2.79 \mathrm{~kg} / \mathrm{m}^{2} ; 49$ males, $42 \pm 11$ years, $172.5 \pm 5.4 \mathrm{~cm}, 73.5 \pm 10.6 \mathrm{~kg}, 24.65 \pm 3.12 \mathrm{~kg} / \mathrm{m}^{2}$ ) healthy, sedentary subjects were selected. The subjects had no cardiovascular disease, diabetes or abnormal glucose tolerance, or any other acute or chronic disease. In the previous 12 months they undertook no regular physical exercises (less 2 times one week and each time less than $20 \mathrm{~min}$, or the total time less than $75 \mathrm{~min}$ in one week). The experimental protocol was ethically conducted in accordance with international standards and as required by the journal [20] and was approved by the Ethics Committee of the Chinese Institute of Sport Science. Before inclusion in the study, subjects were informed of the objectives and procedures and then provided their written, informed consent. After having their initial measurements taken, the participants were requested to climb a hill at their preferred velocity on a fixed route once a week for 16 weeks. The preferred velocity was the maximum speed that the subject could maintain steadily while continuously climbing. The participants were not permitted to carry out other regular moderate and vigorous physical exercises. There were no injuries over the course of the study.

Energy expenditure was measured as climbing was undertaken over a 16-week period at the end of September and in early October. We selected 8 days which had roughly the same pleasant temperature $\left(19 \pm 2{ }^{\circ} \mathrm{C}\right)$ and atmospheric pressure (978 \pm 6 mbar). Among 98 subjects, 77 subjects (40 female, $44 \pm 10$ years, $161.5 \pm 6.3 \mathrm{~cm}, 58.8 \pm 8.7 \mathrm{~kg} ; 37$ male, $40 \pm 12$ years, $172.8 \pm 5.1 \mathrm{~cm}, 72.3 \pm 11.4 \mathrm{~kg}$ ) had time and were willing to participate in the energy expenditure experiments when climbing. One week after the climbing energy expenditure measurements were taken, body composition, $\mathrm{RMR}$, and $\mathrm{VO}_{2}$ max were determined again for the 98 subjects.

\section{Body composition}

Anthropometric measurements were taken on the first test session and included, weight and height (Jianmin II, Beijing Xin Dong Hua Teng, Beijing, China), which were measured with the subjects wearing only their underwear. Height was taken to the nearest $0.1 \mathrm{~cm}$ using a calibrated stadiometer (Jianmin II, Beijing Xin Dong Hua Teng, Beijing, China), and weight (Jianmin II, Beijing Xin Dong Hua Teng, Beijing, China to the nearest $0.1 \mathrm{~kg}$ using an electronic platform scale. Body composition and bone mineral density (BMD) were determined by the whole body dual energy X-ray absorptiometry scan (GE LUNAR DPX system, Madison, WI). Body fat percentage (fat\%), fat mass, and muscle mass were reported for different parts, left arm, left leg, left trunk, left whole body, right arm, right leg, right trunk, right whole body, upper whole body, lower whole body and whole body, respectively. Bone mineral density were also reported for different parts, left arm, left leg, left trunk, left whole body, right arm, right leg, right trunk, hip, rib, pelvis, spine and whole body, respectively.

\section{Resting metabolic rate}

Resting metabolic rate (RMR) was measured by indirect calorimetry using measurement of $\mathrm{VO}_{2}$ and $\mathrm{VCO}_{2}$ (MetaMax 3B, Cortex, Biophysik, Germany) [28]. The MetaMax 3B system analyzer unit was calibrated according to the manufacturer's instructions before each testing session. Early in the morning (7:00 a.m.), the subjects came to the laboratory after an overnight 12-h fast and abstinence from smoking, caffeine and alcohol [8]. Subjects were also required not to have undertaken any vigorous physical activity in the $48 \mathrm{~h}$ prior to testing. Each participant was familiarized with the procedures and equipment used for the RMR analysis, and had at least $10 \mathrm{~min}$ to rest before the study commenced. The test room was comfortably appointed with minimal light and noise. Ambient room temperature was maintained at $\sim 22 \pm 1{ }^{\circ} \mathrm{C}$. The subjects were supine in a bed and were monitored periodically to ensure that they remained awake but as 
quiet as possible before and throughout the entire RMR session. After the RER was between 0.7 with 0.8, METs was approximately equal to 1.0 , and the $\mathrm{VO}_{2}(\mathrm{ml} / \mathrm{min} / \mathrm{kg})$ was about $3.5 \mathrm{ml} /$ $\mathrm{min} / \mathrm{kg}$, the gas was formally collected for $20 \mathrm{~min}$. $\mathrm{A} \mathrm{VO}_{2}$ variation of $<25 \mathrm{ml} / \mathrm{min}$ was used to determine whether the collection was acceptable. Testing lasted $20 \mathrm{~min}$, with the first $5 \mathrm{~min}$ being disregarded [8]. Energy expenditure was calculated from the mean respiratory gas exchange of the last $15 \mathrm{~min}$ according to Weir equation: $\mathrm{EE}(\mathrm{kJ} / \mathrm{min})=\left[3.9 \times \mathrm{VO}_{2}(\right.$ litres $/ \mathrm{min})+1.1 \times \mathrm{VCO}_{2}$ (liters/min)] $\times 4.2[54]$.

\section{Maximal oxygen uptake}

Maximal oxygen uptake $\left(\mathrm{VO}_{2} \mathrm{max}\right)$ was measured breath-by breath (MetaMax 3B, Cortex, Biophysik, Germany). After being provided with instructions on how to use the bicycle ergometer (Ergoselect 100, Ergoline, Germany), subjects performed a brief 5 -min warm-up at $20 \mathrm{~W}$. The technicians explained to each subject the rating of perceived exertion (RPE) (Borg 1974) and rating of perceived breathlessness (RPB) according to the Borg scale of $6-20$ and $0-10$, respectively, and then instructed him or her how to show the values during the measurement process. Maximal oxygen uptake was determined by the following continuous incremental intensity protocol. The initial intensity on the bicycle ergometer was $25 \mathrm{~W}$ and $20 \mathrm{~W}$ at $60 \mathrm{rpm}$ for men and women, respectively and was increased by $25 \mathrm{~W}$ or $20 \mathrm{~W}$ every 2 min until volitional exhaustion. RPE and RPB were recorded at the end of the 2-min load by having the subject point to a printed chart. The test was deemed to be a valid maximal test if at least 3 of the following criteria were met during the last completed stage [22]: a plateau in $\mathrm{VO}_{2}$ despite increasing exercise intensity; subject was no longer able to maintain the required intensity; a respiratory exchange ratio exceeding 1.10; achievement of agepredicted HRmax and a rating of perceived exertion of 20. Breath-by-breath data for ventilation (VE), oxygen consumption $\left(\mathrm{VO}_{2}\right)$, carbon dioxide production $\left(\mathrm{VCO}_{2}\right)$, and respiratory exchange ratio (RER) were averaged over 10-s intervals and exported to an Excel spreadsheet prior to analysis. Heart rate was recorded via a chest strap transmitter (polar RS400, Polar Electro, Kempele, Finland), which was coded for the expired air analyzer telemetry receiver. The HR data was entered into the analyzer data file along with the breath-by-breath expired air analysis data and were averaged over 10 -s intervals for final data analysis. The HR data were filtered through visual editing to eliminate undesirable noise or premature beats.

\section{Energy expenditure when climbing}

Energy expenditures at different slopes were determined with a portable gas analysis system (MetaMax 3B, Cortex, Biophysik, Germany). The hill has a peak altitude of $565 \mathrm{~m}$, and participants climbed a specific route to the summit of the hill once a week (total distance $=2.43 \mathrm{~km}$ ) ( $\bullet$ Fig. 1 ), with total climb time being recorded each time. After 16 weeks, we measured the energy expenditure of climbing at 4 different slope angles. Subjects were instructed on the test procedures, and performed the climbing at least $2 \mathrm{~h}$ post-prandial to reduce the influence from the thermic effect of food on overall energy expenditure [35]. We selected 2 parts of the climbing route to measure the energy expenditure of hill climbing ( $\bullet$ Fig. 1 ). The first part has a relatively stable slope, while the second part has steps as well as 3 relatively stable slopes. 5 markers were placed ( $\bullet$ Fig. 1 ) along the route, with marker 1 being the starting point located $1.16 \mathrm{~km}$ from the park gate. The subjects climbed to the marker 1 from the gate at their usual speed and then rested for $20 \mathrm{~min}$. During this time the MetaMax 3B system was attached to the subjects, as was the heart rate monitor (Polar RS800, Polar Electro, Kempele, Finland). Marker 2 was the end of the first part of the route. At marker 2, expired air data were recorded continuously during a 20 -min sitting recovery period immediately after climbing. The 20-min recovery period was selected to provide an assessment of most of the excess post-exercise oxygen consumption (EPOC). Following the 20-min recovery, participants were allowed to breathe without the facemask and drink water, but were not allowed to eat food or drink any calorie-containing beverages for several minutes. Marker 2 was also the start point of the second part of the route. The distance between marker 2 and marker 3 is the second slope, marker 3 and marker 4 the third slope, and marker 4 and marker 5 the fourth slope. Marker 5 is the end of the second part, at which point 20-min sitting recovery expired air data were also collected.

Subjects were requested to climb at a brisk, rhythmic and constant velocity at their preferred pace as their usual climbing. They were to take only a single step at a time, and running was not allowed. They were not allowed to stop or use the rails for support throughout the climb. An investigator accompanied each subject on his or her climb to ensure compliance and noted down the subject's climb time with a stopwatch as well as RPB and RPE using scale and heart rate at the 5 marker spots and the 2 recovery points. We used the mean value of $\mathrm{VO}_{2}$ and $\mathrm{VCO}_{2}$ for the 3-5 min after reaching a steady state in the respective activities for calculating energy expenditure.

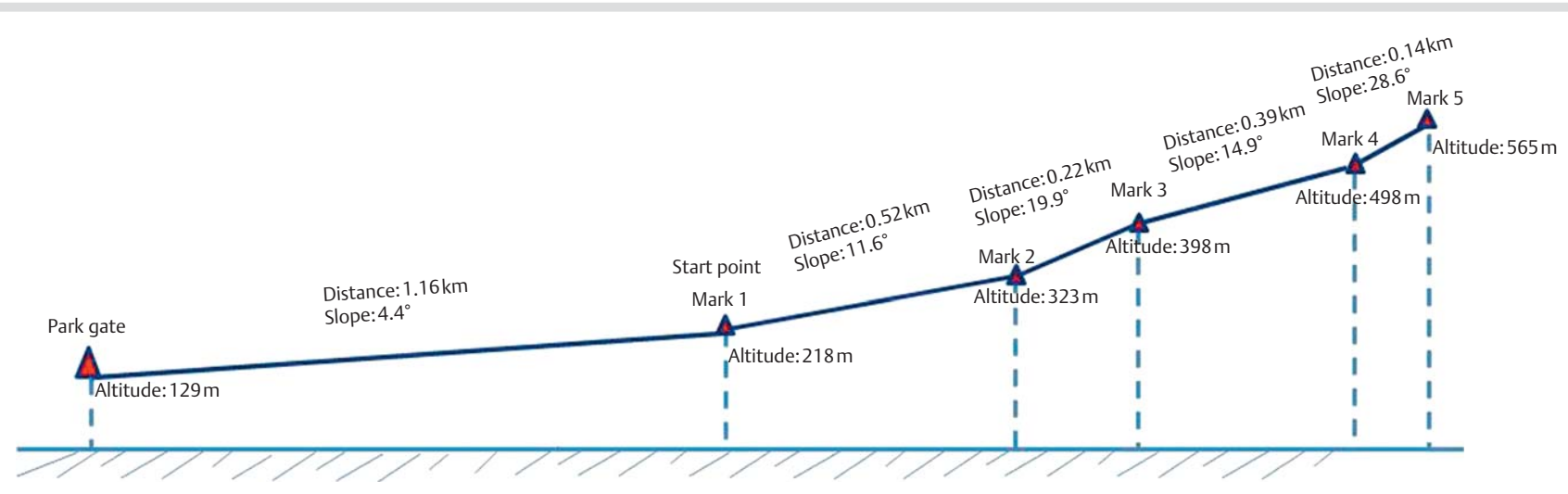

Fig. 1 Hill and energy expenditure measurement route details. 


\section{Statistical analysis}

Statistical analyses were performed using SPSS16.0 software (SPSS, Inc., Chicago, IL).), and descriptive data are presented as mean \pm SD. All measurement indices are normally distributed. Paired samples T test was used to compare the measurement parameters responses before and after the climbing program. Statistical significance was set at $\mathrm{P}<0.05$. The differences in energy expenditure among the 4 slopes were analyzed by a general linear model repeated measure. To compare the main effect of the slopes, the Bonferroni test was selected. To minimize the risk of statistical type I error arising from inter-slopes comparisons, the statistical analyses were corrected using Bonferroni's adjustments, where $\mathrm{P}<0.05 / 4$ (the number of slopes). Linear regression analyses were employed to obtain the equation for calculating energy expenditure and the subjects' preferred speed when climbing. The independent factors are gender, age, height, weight, $\mathrm{VO}_{2} \max (1 / \mathrm{min}, \mathrm{ml} / \mathrm{kg} / \mathrm{min}), \mathrm{RPE}, \mathrm{RPB}, \mathrm{RER}$, slopes and velocity. The relation between the subjects' preferred speed and gender, age, height, weight, $\mathrm{VO}_{2} \mathrm{max}(\mathrm{l} / \mathrm{min}, \mathrm{ml} / \mathrm{kg} /$ $\mathrm{min}$ ) and slope was determined by regression analysis.

\section{Result}

$\nabla$

The average time of the 16 climbing sessions (ascent and decent) was $104 \pm 17 \mathrm{~min}$ and $121 \pm 17 \mathrm{~min}$ for males and females, respectively. Following the completion of the climbing program, body composition presented different change patterns. In males, body weight $(\mathrm{P}=0.007)$, BMI $(\mathrm{P}=0.006)$, whole fat mass $(\mathrm{P}=0.049)$ and leg fat mass $(\mathrm{P}=0.032)$ significantly decreased. Fat $(\%)$ showed a declining trend, but the difference was not significant $(\mathrm{P}=0.068)$. Other parameters did not significantly change $(P>0.05)$. In females, fat ( $\%)(P=0.010)$, fat mass $(P=0.044)$, and leg fat mass $(\mathrm{P}=0.006)$ significantly decreased, and whole muscle mass increased significantly $(P=0.021)$, while other parameters were not significantly changed ( $\bullet$ Table 1 ).

Cardiorespiratory fitness after the intervention is shown in 0 Table 2. In males, the absolute $(P=0.003)$ and relative $(\mathrm{P}=0.001)$ oxygen consumption uptake and VE $(\mathrm{P}<0.001)$ are significantly improved. In females, significant enhancements are also observed for the absolute $(\mathrm{P}<0.001)$ and relative $(\mathrm{P}<0.001)$ oxygen consumption uptake and $\mathrm{VE}(\mathrm{P}<0.001)$. Simultaneously, the HR increased insignificantly $(\mathrm{P}=0.039)$.

Pre-intervention and post-intervention RMR values are presented in $\odot$ Table 3. Absolute values for RMR remained unal-

Table 1 Body composition changes following hill climbing program.

\begin{tabular}{|c|c|c|c|c|c|c|}
\hline & \multicolumn{3}{|c|}{ Male $(n=49)$} & \multicolumn{3}{|c|}{ Female $(n=49)$} \\
\hline & before & after & $\mathbf{P}$ & before & after & $\mathbf{P}$ \\
\hline body weight & $73.5 \pm 10.6$ & $72.7 \pm 9.8$ & 0.007 & $59.2 \pm 8.3$ & $58.8 \pm 8.3$ & 0.282 \\
\hline BMI & $24.65 \pm 3.12$ & $24.38 \pm 2.87$ & 0.006 & $22.78 \pm 2.79$ & $22.64 \pm 2.74$ & 0.290 \\
\hline fat (\%) & $24.4 \pm 7.4$ & $24.0 \pm 7.1$ & 0.068 & $34.0 \pm 7.2$ & $32.9 \pm 7.8$ & 0.010 \\
\hline whole fat mass $(\mathrm{kg})$ & $18.01 \pm 6.88$ & $17.52 \pm 6.44$ & 0.049 & $19.99 \pm 6.36$ & $19.37 \pm 6.52$ & 0.044 \\
\hline leg fat mass $(\mathrm{kg})$ & $4.71 \pm 1.75$ & $4.55 \pm 1.65$ & 0.032 & $6.72 \pm 1.97$ & $6.42 \pm 2.01$ & 0.006 \\
\hline whole muscle mass $(\mathrm{kg})$ & $53.42 \pm 5.26$ & $53.55 \pm 5.17$ & 0.426 & $37.55 \pm 3.74$ & $38.22 \pm 4.03$ & 0.021 \\
\hline leg mass $(\mathrm{kg})$ & $18.26 \pm 2.26$ & $18.19 \pm 2.20$ & 0.581 & $12.45 \pm 1.69$ & $12.39 \pm 1.63$ & 0.547 \\
\hline lower muscle mass (leg mass + hip mass) & $26.14 \pm 3.01$ & $25.95 \pm 2.94$ & 0.275 & $17.83 \pm 2.22$ & $17.80 \pm 2.22$ & 0.806 \\
\hline bone mineral density & $1.225 \pm 0.085$ & $1.226 \pm 0.092$ & 0.809 & $1.121 \pm 0.091$ & $1.128 \pm 0.090$ & 0.112 \\
\hline
\end{tabular}

BMI: body mass index

Table 2 Cardiorespiratory capacity changes following hill climbing program.

\begin{tabular}{|c|c|c|c|c|c|c|}
\hline & \multicolumn{3}{|c|}{ Male $(n=49)$} & \multicolumn{3}{|c|}{ Female $(n=49)$} \\
\hline & before & after & $\mathbf{P}$ & before & after & $\mathbf{P}$ \\
\hline $\mathrm{VO}_{2} \max (\mathrm{I} / \mathrm{min})$ & $2.350 \pm 0.332$ & $2.478 \pm 0.343$ & 0.003 & $1.529 \pm 0.240$ & $1.683 \pm 0.286$ & $<0.001$ \\
\hline $\mathrm{VO}_{2} \max (\mathrm{ml} / \mathrm{min} / \mathrm{kg})$ & $32.68 \pm 7.14$ & $34.68 \pm 6.77$ & 0.001 & $26.32 \pm 4.87$ & $29.03 \pm 5.09$ & $<0.001$ \\
\hline $\operatorname{VE}(1 / \min )$ & $82.68 \pm 15.55$ & $95.24 \pm 17.55$ & $<0.001$ & $51.62 \pm 9.26$ & $66.91 \pm 12.57$ & $<0.001$ \\
\hline HRmax & $173 \pm 16$ & $173 \pm 14$ & 0.832 & $164 \pm 13$ & $167 \pm 11$ & 0.039 \\
\hline RPE & $17 \pm 2$ & $17 \pm 2$ & 0.102 & $17 \pm 2$ & $17 \pm 2$ & 0.078 \\
\hline RPB & $7 \pm 2$ & $7 \pm 2$ & 0.077 & $7 \pm 2$ & $7 \pm 2$ & 0.852 \\
\hline
\end{tabular}

RPE: rating of perceived exertion; RPB: rating of perceived breathlessness

Table 3 Resting metabolic rate changes following hill climbing program.

\begin{tabular}{|c|c|c|c|c|c|c|}
\hline & \multicolumn{3}{|c|}{ Male $(n=49)$} & \multicolumn{3}{|c|}{ Female $(n=49)$} \\
\hline & before & after & $\mathbf{P}$ & before & after & $\mathbf{P}$ \\
\hline $\mathrm{VO}_{2}(1 / \min )$ & $0.280 \pm 0.031$ & $0.292 \pm 0.025$ & 0.155 & $0.218 \pm 0.030$ & $0.219 \pm 0.031$ & 0.931 \\
\hline $\mathrm{VCO}_{2}(1 / \mathrm{min})$ & $0.219 \pm 0.026$ & $0.233 \pm 0.024$ & 0.041 & $0.168 \pm 0.022$ & $0.172 \pm 0.022$ & 0.289 \\
\hline RER & $0.79 \pm 0.07$ & $0.80 \pm 0.05$ & 0.449 & $0.77 \pm 0.06$ & $0.79 \pm 0.05$ & 0.329 \\
\hline $\mathrm{EE}(\mathrm{kJ} / \mathrm{min})$ & $5.59 \pm 0.59$ & $5.84 \pm 0.50$ & 0.105 & $4.37 \pm 0.59$ & $4.37 \pm 0.59$ & 0.775 \\
\hline $\mathrm{EE}(\mathrm{kJ} / \mathrm{min} / \mathrm{kg})$ & $0.076 \pm 0.013$ & $0.080 \pm 0.013$ & 0.054 & $0.077 \pm 0.008$ & $0.077 \pm 0.008$ & 0.161 \\
\hline $\mathrm{EE}(\mathrm{kJ} / \mathrm{min} / \mathrm{muscle}(\mathrm{kg}))$ & $0.101 \pm 0.013$ & $0.109 \pm 0.013$ & 0.051 & $0.118 \pm 0.013$ & $0.113 \pm 0.013$ & 0.161 \\
\hline
\end{tabular}

RMR: resting metabolic rate; EE: energy expenditure 
tered after climbing for both sexes. Results showed an increasing trend when RMR was expressed relative to body weight $(P=0.054)$ and muscle mass $(P=0.051)$ in males, and no significant change in females.

- Table 4 described the results of preferred velocity and energy expenditure under different slope angles. The preferred velocity significantly declined as slope increased $(\mathrm{P}<0.001)$. $\mathrm{Y}$ (preferred speed, $\mathrm{km} / \mathrm{h})=5.992+(-0.009 \times$ age $)+(-0.033 \times$ weight $)+0.249 \times$ $($ female $=1$, and male $=2)+0.781 \times \mathrm{VO}_{2}(1 / \mathrm{min})+(-0.100 \times$ slope $)$ (adjusted R square $=0.776$ ). Males exhibited marginally yet significantly lower energy expenditure at a slope of $11.6^{\circ}$ than at a slope of $14.9^{\circ}(\mathrm{P}=0.012)$ or $19.9^{\circ}(\mathrm{P}=0.010)$. Other post-hoc pairwise comparisons did not reveal significance for either males or females. Linear regression analysis to predict the energy expenditure when climbing yielded the following equation: $Y(E E, k J m i n)=[1.724 \times($ female $=1$, and male $=2)+(-0.072$ $\times$ age $)+0.106 \times$ weight $+0.024 \times \mathrm{HR}+0.136 \times$ slope $+1.487 \times$ velocity] $\times 4.2$. (adjusted $R$ square $=0.619$ ).

\section{Discussion}

$\nabla$

The main and novel finding of our study was that once weekly hill climbing significantly improved cardiorespiratory fitness and the energy cost of approximately 50.4 and $33.6 \mathrm{~kJ} / \mathrm{min}$ under different slopes at subjects' preferred hill climbing speed in both male and female participants.

Hill climbing elicited a peak HR, which increased to above $86 \%$ and $94 \%$ HRmax attained in the laboratory in males and females, respectively. The METs under 4 slopes are approximately, but have gender difference of about 9 and 8 METs for males and females, respectively, which is similar to stair climbing. Subjects ascended 11 stories consisting of 22 flights of stairs for a total of 180 steps (each flight of stairs has 8 steps except for the lowest flight, which has 12 steps.). Each step was $15 \mathrm{~cm}$ in height, for a total vertical displacement of $27.0 \mathrm{~m}$. The intensity during ascent is 9.6 METs [51]. At a stepping rate of $70 \mathrm{step} / \mathrm{min}$, METs is 8.6 [3]. Compared with other common exercise modes, the METs of hill climbing is equivalent to running at a pace of about $9.6 \mathrm{~km} / \mathrm{h}$ and $8.0 \mathrm{~km} / \mathrm{h}$ for males and females [1]. The METs of physical activity is $\geq 6.0$ [1], thus making hill climbing at subjects' preferred velocity a vigorous-intensity physical activity. Subjects can sustain 2 or more hours of climbing, but it is difficult for them to insist on running or stair climbing the same time.

To our knowledge, this is the first study to examine energy expenditure during low-altitude hill climbing at low altitude under different slopes for health improvement. In the present study, the energy expenditures observed under different slopes at subjects' preferred speed were similar. Prior to the testing, we hypothesized that the increasing slope would increase the EE. Linear regression analysis displayed that the most important factor influencing EE was climbing velocity. In our experimental design, when the slope angles increased, the measurement distance and climbing time decreased, while climbing velocity also dropped significantly. However heart rate increased significantly in all subjects, with some even reaching their maximal heart rate. Subjects were requested to perform the preferred walking velocity, which was the maximum speed that the subjects can consistently maintain, while continually climbing. This indicated that the subjects might have no capacity to keep the same velocity as the slopes are steeper. Hence the EE appeared not to significantly increase when the slopes rose, simply due to the fact that the velocity was slower over which the participants climbed.

Table 4 Energy expenditure when climbing under 4 different slope angles.

\begin{tabular}{|c|c|c|c|c|c|c|c|c|c|c|}
\hline & $\begin{array}{c}\text { Slope1(11.6 }) \\
\text { (a) }\end{array}$ & $\begin{array}{c}\text { Slope2(19.9 }) \\
\text { (b) }\end{array}$ & $\begin{array}{c}\text { Slope3 }\left(14.9^{\circ}\right) \\
\text { (c) }\end{array}$ & $\begin{array}{c}\text { Slope } 4\left(28.6^{\circ}\right) \\
\text { (d) }\end{array}$ & a vs. b & a vs. c & a vs. d & b vs. c & b vs. d & c vs. d \\
\hline \multicolumn{11}{|l|}{ male $(n=37)$} \\
\hline preferred velocity & $3.35 \pm 0.43$ & $2.26 \pm 0.35$ & $2.82 \pm 0.32$ & $1.64 \pm 0.32$ & $<0.001$ & $<0.001$ & $<0.001$ & $<0.001$ & $<0.001$ & $<0.001$ \\
\hline $\mathrm{VO}_{2}(\mathrm{ml} / \mathrm{min} / \mathrm{kg})$ & $30.90 \pm 5.31$ & $33.37 \pm 7.25$ & $33.74 \pm 7.84$ & $33.04 \pm 7.95$ & 0.015 & 0.010 & 0.087 & 0.350 & 0.579 & 0.139 \\
\hline METs & $8.83 \pm 1.52$ & $9.53 \pm 2.07$ & $9.64 \pm 2.24$ & $9.44 \pm 2.27$ & 0.015 & 0.010 & 0.087 & 0.350 & 0.579 & 0.139 \\
\hline $\mathrm{EE}(\mathrm{kJ} / \mathrm{min})$ & $46.20 \pm 7.98$ & $50.82 \pm 10.92$ & $51.24 \pm 11.76$ & $50.40 \pm 11.34$ & 0.012 & 0.010 & 0.077 & 1.000 & 1.000 & 1.000 \\
\hline RER & $0.98 \pm 0.19$ & $1.09 \pm 0.20$ & $1.08 \pm 0.18$ & $1.12 \pm 0.19$ & 0.012 & 0.005 & $<0.001$ & 1.000 & 0.790 & 0.001 \\
\hline HR & $148 \pm 18$ & $160 \pm 19$ & $168 \pm 18$ & $172 \pm 18$ & $<0.001$ & $<0.001$ & $<0.001$ & $<0.001$ & $<0.001$ & $<0.001$ \\
\hline \%HRmax & $86 \pm 10$ & $92 \pm 12$ & $97 \pm 11$ & $100 \pm 10$ & $<0.001$ & $<0.001$ & $<0.001$ & $<0.001$ & $<0.001$ & $<0.001$ \\
\hline RPE & $10 \pm 2$ & $11 \pm 2$ & $12 \pm 2$ & $13 \pm 3$ & 0.208 & 0.057 & $<0.001$ & 1.000 & $<0.001$ & $<0.001$ \\
\hline RPB & $2 \pm 1$ & $3 \pm 2$ & $4 \pm 2$ & $5 \pm 3$ & 0.074 & 0.003 & $<0.001$ & 0.017 & $<0.001$ & 0.075 \\
\hline climb time (min) & $9 \pm 1$ & $6 \pm 1$ & $8 \pm 1$ & $5 \pm 1$ & & & & & & \\
\hline $\begin{array}{l}20 \text { min recovery } \\
E E(k J / m i n)\end{array}$ & $9.20 \pm 1.76$ & & & $10.63 \pm 2.52$ & & & & & & \\
\hline \multicolumn{11}{|l|}{ female $(n=40)$} \\
\hline preferred velocity & $3.21 \pm 0.39$ & $1.96 \pm 0.32$ & $2.40 \pm 0.43$ & $1.47 \pm 0.33$ & $<0.001$ & $<0.001$ & $<0.001$ & $<0.001$ & $<0.001$ & $<0.001$ \\
\hline $\mathrm{VO}_{2}(\mathrm{ml} / \mathrm{min} / \mathrm{kg})$ & $30.20 \pm 5.91$ & $29.82 \pm 6.80$ & $29.68 \pm 7.69$ & $28.57 \pm 7.64$ & 0.727 & 0.667 & 0.159 & 0.680 & 0.008 & 0.003 \\
\hline METs & $8.63 \pm 1.69$ & $8.52 \pm 1.94$ & $8.48 \pm 2.20$ & $8.16 \pm 2.18$ & 0.727 & 0.667 & 0.159 & 0.680 & 0.008 & 0.003 \\
\hline $\mathrm{EE}(\mathrm{kJ} / \mathrm{min})$ & $35.28 \pm 6.72$ & $35.28 \pm 7.56$ & $34.86 \pm 8.82$ & $34.02 \pm 8.82$ & 1.000 & 1.000 & 1.000 & 1.000 & 0.047 & 0.264 \\
\hline RER & $1.02 \pm 0.19$ & $1.09 \pm 0.21$ & $1.03 \pm 0.16$ & $1.09 \pm 0.19$ & 0.518 & 1.000 & 0.562 & 0.001 & 1.000 & $<0.001$ \\
\hline $\mathrm{HR}$ & $156 \pm 17$ & $165 \pm 9$ & $170 \pm 10$ & $173 \pm 11$ & 0.049 & 0.002 & $<0.001$ & $<0.001$ & $<0.001$ & 0.009 \\
\hline \%HRmax (\%) & $94 \pm 11$ & $100 \pm 6$ & $102 \pm 6$ & $105 \pm 6$ & 0.007 & $<0.001$ & $<0.001$ & $<0.001$ & $<0.001$ & 0.001 \\
\hline RPE & $12 \pm 2$ & $13 \pm 2$ & $13 \pm 2$ & $15 \pm 3$ & 1.000 & 0.130 & $<0.001$ & 0.848 & $<0.001$ & $<0.001$ \\
\hline RPB & $3 \pm 1$ & $4 \pm 2$ & $4 \pm 2$ & $6 \pm 2$ & 0.001 & $<0.001$ & $<0.001$ & 0.030 & $<0.001$ & $<0.001$ \\
\hline climb time (min) & $10 \pm 1$ & $7 \pm 1$ & $10 \pm 2$ & $6 \pm 1$ & & & & & & \\
\hline $\begin{array}{l}20 \text { min recovery } \\
E E(k J / m i n)\end{array}$ & $6.80 \pm 2.60$ & & & $7.39 \pm 3.24$ & & & & & & \\
\hline
\end{tabular}

\% HRmax is computed by dividing climbing $\mathrm{HR}$ by $\mathrm{HRmax}$ obtained in the $\mathrm{VO}_{2}$ max measurement 
At subjects' preferred velocity, energy expenditure of climbing has a gender difference of 50.4 and $33.6 \mathrm{~kJ} / \mathrm{min}$ for males and females, respectively. In 10 experienced male climbers (30.0 0.9 years), energy expenditures for cross-country skiing and alpine climbing at moderate altitude under high degrees of difficulty and risk exposure lasting approximately $30 \mathrm{~h}$ were $57.12 \pm 2.1 \mathrm{~kJ} /$ $\min$ and $54.18 \pm 2.94 \mathrm{~kJ} / \mathrm{min}$, respectively [5]. In 14 participants ( 8 males and 6 females), stair climbing trials consisted of 86 steps and with a total vertical displacement of $14.05 \mathrm{~m}$ (each step averaged $16.3 \mathrm{~cm}$ in height) over 8 flights and 5 floors. The EE of single-step climbing used $35.7 \mathrm{~kJ} / \mathrm{min}$, and $38.64 \mathrm{~kJ} / \mathrm{min}$ for double-step climbing [17]. In another stair climbing study, the EE was $42.85 \mathrm{~kJ} / \mathrm{min}$ [51]. Hence, in males, the EE in hill climbing was higher than that of stair climbing, and in females, the EE was similar or lower. The EE of hill climbing was correlated with gender, age, weight, slope and velocity. The maximal steady climbing speed was also decided by gender, age, weight and slope. An energy expenditure of approximately $4200 \mathrm{~kJ} /$ week is associated with lower rates of cardiovascular disease (CVD) and premature mortality [13]. Thus, $90 \mathrm{~min}$ and $125 \mathrm{~min}$ of hill ascent for males and females can meet this requirement.

Contrary to our hypothesis that RMR would increase as a result of hill climbing training, the RMR was not significantly altered. Previous studies have produced inconsistent results, which reported increases ranging from $3 \%$ to $7.7 \%[6,10,32,37,39]$, no change $[27,40]$ or an $8 \%$ decrease in $\operatorname{RMR}[6,40]$ with exercise training and those investigated primarily obese women [6], elderly people [32,37], postmenopausal women $[39,40]$ and active men [10]. Long-term effects of training include increases in RMR due to increases in lean muscle mass [47]. The effects of resistance training enhanced RMR through an increase in fat-free mass $2.3 \mathrm{~kg}$ [10], $1.90 \mathrm{~kg}$ [6], $1.6 \mathrm{~kg}$ [37] and $1.1 \mathrm{~kg}$ [39]. Other resistance training studies have shown that RMR did not change significantly, even though the fat-free mass increased $2.2 \mathrm{~kg}$ [9]. In our study, the mean free-fat mass in previous healthy sedentary females increased $0.67 \mathrm{~kg}$ after hill climbing, and RMR did not significantly increase. The inconsistency might result from the different training programs and fitness levels.

After a day per week of hill climbing for 16 weeks, the whole body fat mass significantly decreased in both sexes. Leg fat mass also significantly declined $0.16 \mathrm{~kg}(3.4 \%)$ and $0.30 \mathrm{~kg}(4.5 \%)$ for males and females, respectively. The whole body muscle mass increased significantly in females, and it presented an incremental trend in males. However, although not significant, leg muscle mass showed a small decrease of $0.07 \mathrm{~kg}(0.4 \%)$ and $0.06 \mathrm{~kg}$ $(0.5 \%)$ for males and females, respectively. Reports on the influence of aerobic exercise training on muscle mass have been equivocal, with some finding decreases $[24,52]$ or no influence $[44,46]$, and several others observing significant whole muscle hypertrophy $[18,19,43]$. The discrepancy in the literature is most likely due to variations in exercise program characteristics and subject populations. 78 healthy, previously untrained men and women aged 19-87 years were studied before and after 4 months of bicycle training (up to $45 \mathrm{~min}$ at $80 \%$ peak heart rate, 3-4 days/week) or control (flexibility) activity. Exercise training improved aerobic capacity $9 \%$ overall, but fat-free mass and resting metabolic rate were unchanged by training [44]. Subjects performed 12 weeks of aerobic exercise training on a cycle ergometer at an intensity of $60-80 \%$ of their maximal heart rate, for $20-45 \mathrm{~min} 3-4$ times per week. Power was progressively increased in $12-\mathrm{W}$ increments to optimize the training response. After training, whole muscle significantly increased by $5 \%$ and
$6 \%$ for males and females, respectively [19]. However, most studies involving strength training [46] or endurance training combined strength training $[42,45]$ showed a significant increase in muscle mass. In our study, fat (\%) only decreased by $0.4 \%$ and $1.1 \%$ for males and females, respectively. When the training program combined strength training, fat (\%) decreased by $2.1 \%$ [23]. It can therefore be speculated that mixing resistance training and climbing might enhance the RMR and produce better fitness results.

Cardiorespiratory fitness has a strong, graded, inverse association with overall, CVD-related and non-CVD-related mortality [26]. An individual's $\mathrm{VO}_{2}$ max is regarded as the strongest predictors of mortality [26], and better cardiorespiratory fitness is associated with a lower risk of all-cause mortality and coronary heart disease (CHD)/CVD. Participants with a maximal aerobic capacity (MAC) of 7.9 METs or more had substantially lower rates of all-cause mortality and CHD/CVD events compared to those with a MAC of less 7.9 METs [25]. Even small improvements in physical fitness are associated with a significantly lowered risk of death [13]. Evidence for a minimum threshold of intensity for benefit is supported in many studies, but not all, and the lack of consistent findings seems to be related to the initial state of fitness and/or conditioning of the subjects [13]. Swain and Franklin reviewed 18 trials involving healthy subjects that measured $\mathrm{VO}_{2}$ max before and after exercise training and found the use of $45 \%$ oxygen uptake reserve $\left(\mathrm{VO}_{2} \mathrm{R}\right)$ and $30 \%$ $\mathrm{VO}_{2} \mathrm{R}$ to be a minimal effective training intensity for more fit subjects ( $>40 \mathrm{ml} / \mathrm{min} / \mathrm{kg}$ ) and less fit subjects ( $<40 \mathrm{ml} / \mathrm{min} / \mathrm{kg}$ ), respectively, despite there being no strong evidence for a threshold intensity. The $\mathrm{VO}_{2} \mathrm{R}$ is the percentage of the difference between maximum and resting $\mathrm{VO}_{2}$ [48]. Another comprehensive review of exercise training in runners determined that "near maximal" (i.e., 95-100\% $\mathrm{VO}_{2} \mathrm{max}$ ) training intensities were needed to improve $\mathrm{VO}_{2} \max$ in well trained athletes, while $70-80 \% \mathrm{VO}_{2}$ max seemed to provide a sufficient stimulus in moderately trained athletes [29]. Thus, a threshold of exercise intensity may vary depending on fitness level, and it may be difficult to precisely define an exact threshold for improving cardiorespiratory fitness. The significant improvement in $\mathrm{VO}_{2} \max$ reported in the present study provides evidence that just $2 \mathrm{~h}$ of hill climbing once a week at the subjects' preferred velocity is sufficient to enhance cardiovascular fitness in sedentary healthy adults.

Following $16-\mathrm{W}$ hill climbing in the present study, the $\mathrm{VO}_{2} \max$ increased $6.1 \%$ and $10.3 \%$ in males and females, respectively. In 8 sedentary young women, stair climbing was progressively increased from one ascent a day in week 1 to 5 ascents a day in weeks 7 and 8 . Training took place 5 days a week on a public access staircase (199 steps), at a stepping rate of 90 steps per minute. Each ascent took about 2 min to complete. The accumulated bouts of stair climbing result in a $17.1 \%$ increase in $\mathrm{VO}_{2} \max$ [4]. The degree of improvement in $\mathrm{VO}_{2}$ max was lower for hill climbing than that of stair climbing [4], but the benefits from hill climbing resulted from only once a week. Once weekly is more suitable for people who are busy and have more actual application.

Ventilation increased significantly, specifically by $29.6 \%$ and $15.2 \%$ for males and females, respectively, indicating an improvement in respiratory muscle function. This may result from expiratory pressure increasing at the beginning of expiration to take advantage of the higher flows available at higher lung volumes or from end expiratory lung volume increasing, thereby shifting the tidal volume closer to total lung capacity, at which point 
higher expiratory flows can be achieved [7]. The ability to augment VE is also impeded by excess body mass [2], resulting in an altered ventilatory pattern in which higher than expected increases in respiratory rate are needed to offset a diminished ability to increase tidal volume. Therefore, hill climbing might have benefits for enhancing lung function in obese persons. In healthy males, increases in plasma interleukin-6 (IL-6) concentration during maximum sustainable voluntary ventilation are attenuated following 6-W inspiratory muscle training by $27 \pm 18 \%$, and the plasma IL- 6 response is dependent upon the level of respiratory muscle work and VE [31]. IL-6 is an energy sensor and acts to stimulate lipolysis, hepatic glucose output and glucose uptake [34]. It is thus speculated that the improvement of VE following the completion of the hill climbing program reflects changes in glucose metabolism, lipolysis and fat oxidation.

\section{Conclusion}

Hill climbing at subjects' preferred velocity is a vigorous-intensity physical activity for energy cost and is equivalent to running at a pace of about $9.6 \mathrm{~km} / \mathrm{h}$ and $8.0 \mathrm{~km} / \mathrm{h}$ for males and females. Performed once weekly, it can enhance cardiorespiratory fitness and reduce fat mass, and can therefore be considered a viable exercise for most people and suitable for promoting physical activity.

\section{Acknowledgements}

\section{$\nabla$}

We gratefully acknowledge the help of all the subjects who took part in the study. Thanks for, Baoxin feng, Wenyuan Shang, and Han Li for their technical assistance. Thanks for the undergraduates, Rui Yang, Lei Zhang, Minxiao Xu, Zhaozhao Wu, Xu Han, Bingqiang Lv, for the parameters' measurement. Thanks for the Chinese Mountaineering association for the recruiting the subjects. This study was supported by grant from Ministry of Science and Technology of the People's Republic of China (Grant code: 2012BAK23B01).

\section{Affiliations}

${ }^{1}$ Biology Center, China Institute of Sport Science, Beijing, China

2 Department of Sport Biochemistry, Beijing Sports University, Beijing, China ${ }^{3}$ Department of Sport Biochemistry, Shandong Sports University, Jinan, China

${ }^{4}$ College of Physical Education, Kyung Hee University, Seoul, Republic of Korea

${ }^{5}$ Department of Research, The Chinese Mountaineering Association, Beijing, China

${ }^{6}$ Sport Biological Center, China Institute of Sport Science, Beijing, China ${ }^{7}$ Department of Sport and Physical Activity, Edge Hill University, Lancashire, United Kingdom

\section{References}

1 Ainsworth BE, Haskell WL, Herrmann SD, Meckes N, Bassett DR Jr, Tudor-Locke C, Greer JL, Vezina J, Whitt-Glover MC, Leon AS. 2011 Compendium of Physical Activities: a second update of codes and MET values. Med Sci Sports Exerc 2011; 43: 1575-1581

2 Arena $R$, Cahalin LP. Evaluation of cardiorespiratory fitness and respiratory muscle function in the obese population. Prog Cardiovasc Nurs 2014; 56: 457-464

3 Bassett DR, Vachon JA, Kirkland AO, Howley ET, Duncan GE, Johnson KR. Energy cost of stair climbing and descending on the college alumnus questionnaire. Med Sci Sports Exerc 1997; 29: 1250-1254

4 Boreham CA, Kennedy RA, Murphy MH, Tully M, Wallace WF, Young I. Training effects of short bouts of stair climbing on cardiorespiratory fitness, blood lipids, and homocysteine in sedentary young women. Br J Sports Med 2005; 39: 590-593
5 Bourrilhon C, Philippe M, Chennaoui M, Van Beers $P$, Lepers $R$, Dussault $C$, Guezennec $C Y$, Gomez-Merino D. Energy expenditure during an ultraendurance alpine climbing race. Wilderness Environ Med 2009; 20: 225-233

6 Byrne HK, Wilmore JH. The effects of a 20-week exercise training program on resting metabolic rate in previously sedentary, moderately obese women. Int J Sport Nutr Exerc Metab 2001; 11: 15-31

7 Chapman RF. The individual response to training and competition at altitude. Br J Sports Med 2013; 47 (Suppl 1): i40-i44

8 Compher C, Frankenfield D, Keim N, Roth-Yousey L. Best practice methods to apply to measurement of resting metabolic rate in adults: a systematic review. J Am Diet Assoc 2006; 106: 881-903

9 Cullinen $K$, Caldwell $M$. Weight training increases fat-free mass and strength in untrained young women. J Am Diet Assoc 1998; 98: 414-418

10 Dolezal BA, Potteiger JA. Concurrent resistance and endurance training influence basal metabolic rate in nondieting individuals. J Appl Physiol 1998; 85: 695-700

11 Donnelly JE, Blair SN, Jakicic JM, Manore MM, Rankin JW, Smith BK. American College of Sports M. American College of Sports Medicine Position Stand. Appropriate physical activity intervention strategies for weight loss and prevention of weight regain for adults. Med Sci Sports Exerc 2009; 41: 459-471

12 Flegal KM, Carroll MD, Kit BK, Ogden CL. Prevalence of obesity and trends in the distribution of body mass index among US adults, 19992010. J Am Med Assoc 2012; 307: 491-497

13 Garber CE, Blissmer B, Deschenes MR, Franklin BA, Lamonte MJ, Lee IM, Nieman DC, Swain DP. American College of Sports Medicine position stand. Quantity and quality of exercise for developing and maintaining cardiorespiratory, musculoskeletal, and neuromotor fitness in apparently healthy adults: guidance for prescribing exercise. Med Sci Sports Exerc 2011; 43: 1334-1359

14 Giles LV, Rhodes EC, Taunton JE. The physiology of rock climbing. Sports Med 2006; 36: 529-545

15 Hall KD, Heymsfield SB, Kemnitz JW, Klein S, Schoeller DA, Speakman $J R$. Energy balance and its components: implications for body weight regulation. Am J Clin Nutr 2012; 95: 989-994

16 Halla PC, Andersen LB, Bull FC, Guthold R, Haskell W, Ekelund U. Lancet Physical Activity Series Working G. Global physical activity levels: surveillance progress, pitfalls, and prospects. Lancet 2012; 380: 247-257

17 Halsey LG, Watkins DA, Duggan BM. The energy expenditure of stair climbing one step and two steps at a time: estimations from measures of heart rate. PloS One 2012; 7: e51213

18 Harber MP, Konopka AR, Douglass MD, Minchev K, Kaminsky LA, Trappe $T A$, Trappe $S$. Aerobic exercise training improves whole muscle and single myofiber size and function in older women. Am J Physiol 2009; 297: R1452-R1459

19 Harber MP, Konopka AR, Undem MK, Hinkley JM, Minchev K, Kaminsky LA, Trappe TA, Trappe S. Aerobic exercise training induces skeletal muscle hypertrophy and age-dependent adaptations in myofiber function in young and older men. J Appl Physiol 2012; 113: 1495-1504

20 Harriss DJ, Atkinson G. Ethical standards in sport and exercise science research: 2014 update. Int J Sports Med 2013; 34: 1025-1028

21 Heath GW, Parra DC, Sarmiento OL, Andersen LB, Owen N, Goenka S, Montes F, Brownson RC. Lancet Physical Activity Series Working G. Evidence-based intervention in physical activity: lessons from around the world. Lancet 2012; 380: 272-281

22 Howley ET, Bassett DR Jr, Welch HG. Criteria for maximal oxygen uptake: review and commentary. Med Sci Sports Exerc 1995; 27: 1292-1301

23 Küpper T, Jacobson V, Westphal C, Müller M, Müller S. Effective weight reduction in patients with metabolic syndrome by an individual sport therapeutic program - an empiric analysis. Med Sport 2011; 15: 219-226

24 Klausen $K$, Andersen LB, Pelle I. Adaptive changes in work capacity, skeletal muscle capillarization and enzyme levels during training and detraining. Acta Physiol Scand 1981; 113: 9-16

25 Kodama S, Saito K, Tanaka S, Maki M, Yachi Y, Asumi M, Sugawara A Totsuka K, Shimano H, Ohashi Y, Yamada N, Sone H. Cardiorespiratory fitness as a quantitative predictor of all-cause mortality and cardiovascular events in healthy men and women: a meta-analysis. J Am Med Assoc 2009; 301: 2024-2035

26 Laukkanen JA, Lakka TA, Rauramaa R, Kuhanen R, Venalainen JM, Salonen $R$, Salonen JT. Cardiovascular fitness as a predictor of mortality in men. Arch Intern Med 2001; 161: 825-831

27 Lee MG, Sedlock DA, Flynn MG, Kamimori GH. Resting metabolic rate after endurance exercise training. Med Sci Sports Exerc 2009; 41: 1444-1451 
28 Macfarlane DJ, Wong P. Validity, reliability and stability of the portable Cortex Metamax 3B gas analysis system. Eur J Appl Physiol 2012; 112: $2539-2547$

29 Midgley AW, McNaughton LR, Wilkinson M. Is there an optimal training intensity for enhancing the maximal oxygen uptake of distance runners?: empirical research findings, current opinions, physiological rationale and practical recommendations. Sports Med 2006; 36: 117-132

30 Miller $A D$, Taylor BJ, Johnson BD. Energy expenditure and intensity levels during a $6170-\mathrm{m}$ summit in the Karakoram mountains. Wilderness Environ Med 2013; 24: 337-344

31 Mills DE, Johnson MA, McPhilimey MJ, Williams NC, Gonzalez JT, Barnett YA, Sharpe GR. Influence of oxidative stress, diaphragm fatigue and inspiratory muscle training on the plasma cytokine response to maximum sustainable voluntary ventilation. J Appl Physiol 2014; 116: 970-979

32 Morio B, Montaurier C, Pickering G, Ritz P, Fellmann N, Coudert J, Beaufrere $B$, Vermorel $M$. Effects of 14 weeks of progressive endurance training on energy expenditure in elderly people. Br J Nutr 1998; 80: 511-519

33 Netzer NC, Chytra R, Kupper T. Low intense physical exercise in normobaric hypoxia leads to more weight loss in obese people than low intense physical exercise in normobaric sham hypoxia. Sleep Breath 2008; 12: 129-134

34 Pedersen BK. Muscular interleukin-6 and its role as an energy sensor. Med Sci Sports Exerc 2012; 44: 392-396

35 Peterman JE, Kram R, Byrnes WC. Factors affecting the increased energy expenditure during passive cycling. Eur J Appl Physiol 2012; 112: $3341-3348$

36 Poehlman ET. A review: exercise and its influence on resting energy metabolism in man. Med Sci Sports Exerc 1989; 21: 515-525

37 Pratley R, Nicklas B, Rubin M, Miller J, Smith A, Smith M, Hurley B, Goldberg $A$. Strength training increases resting metabolic rate and norepinephrine levels in healthy 50- to 65-yrs.-old men.J Appl Physiol 1994; 76: 133-137

38 Ramage S, Farmer A, Apps Eccles K, McCargar L. Healthy strategies for successful weight loss and weight maintenance: a systematic review. Appl Physiol Nutr Metab 2014; 39: 1-20

39 Ryan AS, Pratley RE, Elahi D, Goldberg AP. Resistive training increases fat-free mass and maintains RMR despite weight loss in postmenopausal women. J Appl Physiol 1995; 79: 818-823

40 Santa-Clara H, Szymanski L, Ordille T, Fernhall B. Effects of exercise training on resting metabolic rate in postmenopausal African American and Caucasian women. Metabolism 2006; 55: 1358-1364
41 Schoffl $V$, Morrison A, Schoffl I, Kupper T. The epidemiology of injury in mountaineering, rock and ice climbing. Med Sport Sci 2012; 58: 17-43

42 Schumann M, Kuusmaa M, Newton RU, Sirparanta AI, Syvaoja H, Hakkinen $A$, Hakkinen $K$. Fitness and lean mass increases during combined training independent of loading order. Med Sci Sports Exerc 2014; 46: $1758-1768$

43 Schwartz RS, Shuman WP, Larson V, Cain KC, Fellingham GW, Beard JC, Kahn SE, Stratton JR, Cerqueira MD, Abrass IB. The effect of intensive endurance exercise training on body fat distribution in young and older men. Metabolism 1991; 40: 545-551

44 Short KR, Vittone JL, Bigelow ML, Proctor DN, Nair KS. Age and aerobic exercise training effects on whole body and muscle protein metabolism. Am J Physiol 2004; 286: E92-E101

45 Sillanpaa E, Hakkinen A, Nyman K, Mattila M, Cheng S, Karavirta L, Laaksonen DE, Huuhka N, Kraemer WJ, Hakkinen K. Body composition and fitness during strength and/or endurance training in older men. Med Sci Sports Exerc 2008; 40: 950-958

46 Sipila S, Suominen $H$. Effects of strength and endurance training on thigh and leg muscle mass and composition in elderly women. J Appl Physiol (1985) 1995; 78: 334-340

47 Speakman JR, Selman C. Physical activity and resting metabolic rate. Proc Nutr Soc 2003; 62: 621-634

48 Swain DP, Franklin BA. VO(2) reserve and the minimal intensity for improving cardiorespiratory fitness. Med Sci Sports Exerc 2002; 34: $152-157$

49 Swift DL, Johannsen NM, Lavie CJ, Earnest CP, Church TS. The role of exercise and physical activity in weight loss and maintenance. Prog Cardiovasc Nurs 2014; 56: 441-447

50 Tate DF, Jeffery RW, Sherwood NE, Wing RR. Long-term weight losses associated with prescription of higher physical activity goals. Are higher levels of physical activity protective against weight regain? Am J Clin Nutr 2007; 85: 954-959

51 Teh KC, Aziz AR. Heart rate, oxygen uptake, and energy cost of ascending and descending the stairs. Med Sci Sports Exerc 2002; 34: 695-699

52 Terrados N, Melichna J, Sylven C, Jansson E. Decrease in skeletal muscle myoglobin with intensive training in man. Med Sport 1986; 128 : 651-652

53 Wadden TA, Webb VL, Moran CH, Bailer BA. Lifestyle modification for obesity: new developments in diet, physical activity, and behavior therapy. Circulation 2012; 125: 1157-1170

54 Weir JB. New methods for calculating metabolic rate with special reference to protein metabolism. J Physiol 1949; 109: 1-9 